\title{
Familia y Tecnociencia: ¿qué nos depara el futuro inmediato?
}

\author{
Joaquín Guerrero Muñoz \\ Universidad de Murcia \\ Luís Álvarez Munárriz \\ Universidad de Murcia
}

Resumen

En esta contribución abordamos el tema de la familia y la tecnociencia. Definimos la tecnociencia como un saber aplicado a todos los ámbitos de la realidad. Nos aproximamos a la cuestión de la familia nuclear y la pareja y exponemos nuestras contribuciones anteriores en torno a la biotecnología humana y la familia que actualizamos y ampliamos. Nos centramos en el impacto que la sindemia de la Covid-19 está teniendo en la vida familiar y seguidamente explicamos la repercusión de los recientes avances de la Ingeniería genética especialmente de la Edición de Genes (CRISPR). Exponemos las disputas que están generando tanto la clonación como la reciente modificación de embriones y finalmente resaltamos la necesidad de seguir investigando para lograr una relación armónica y favorable con la tecnociencia.

Palabras clave

Familia nuclear; Tecnociencia; Clonación; Edición de genes; Covid-19

Códigos JEL: O39, Z13, Y80, E00
FAMILY AND TECHNO-SCIENCE: WHAT THE IMMEDIATE FUTURE WILL BRING?

Abstract

In this contribution we address the issue of family and technoscience. We define techno-science as knowledge applied to all areas of reality. We approach on the topic of the nuclear family and the couple and then we expose our previous contributions on family and human biotechnology and we update and expand our knowledge on it. We focus on the impact that the Covid-19 syndemic is having on family life and then we explain the impact that the latest advances in Genetic Engineering, especially Gene Editing (CRISPR) are taking into account. We expose the disputes that are generating both the cloning and the recent modification of embryos and we finally highlight the need to continue researching to achieve a harmonious and favourable relationship with techno-science.

Keywords

Nuclear family; Techno-science; Cloning; Gene editing; Covid-19

JEL codes: O39, Z13, Y80, E00

Fecha de recepción del original: 26 de abril de 2021; versión definitiva: 20 de junio de 2021.

Joaquín Guerrero Muñoz, Área de Trabajo Social y Servicios Sociales. Dpto. Trabajo Social y Servicios Sociales, Universidad de Murcia Tel.: +34 868889107; E-mail: jguerrero@um.es; ORCID ID: https://orcid.org/0000-0003-0602-5527.

Luís Álvarez Munárriz, Área de Antropología Social, Dpto. Ciencias Políticas, Antropología Social y Hacienda Pública, Universidad de Murcia Tel.: +34 679550236; E-mail: munarriz@um.es; ORCID ID: https://orcid.org/0000-0003-0612-2765. 


\title{
Familia y Tecnociencia: ¿qué nos depara el futuro inmediato?
}

\author{
Joaquín Guerrero Muñoz \\ Universidad de Murcia \\ Luís Álvarez Munárriz \\ Universidad de Murcia
}

Introducción

En esta contribución abordamos el tema de la familia y la tecnociencia. Para poder iniciar y avanzar en esta exposición debemos comenzar fijando cómo se concibe esta institución. En la literatura científica se pueden encontrar múltiples definiciones. Ahora bien, para evitar discusiones consideramos suficiente esta simple descripción: una institución social básica compuesta de padres e hijos que comparten un proyecto de vida en un espacio común. De una manera más rigurosa la podemos describir como un sistema que consta de elementos (padres e hijo/s íntimamente unidos) y formando subsistemas (conyugal y filial) relacionados según los principios de la causalidad circular. Se entiende así el sistema familiar humano como una red de relaciones, que une a cada miembro de la familia con otros y que responde dinámicamente a su entorno y a las condiciones a las que todos los miembros deben adaptarse. El comportamiento de cada miembro de la familia influye en el de los demás hasta cierto punto (Papero et al., 2018). La revolución que en las sociedades desarrolladas produjo la irrupción de la mujer en el mundo del trabajo, así como la actividad esencial de las mujeres de a pie, generó una progresiva y profunda transformación de la estructura y evolución de la familia.

Uno de los factores que influyó decisivamente en estos cambios es la tecnociencia. Se puede describir como un saber teórico aplicado basado en la estrecha cooperación de científicos, ingenieros y empresarios. Su objetivo último no es solamente conocer sino también transformar y dominar el mundo. Es el sistema ideal que configura nuestra cultura y se resuelve y concreta en la construcción de modelos. El modelo que consideramos más fértil es el ecosistémico de corte sintético. Está orientado y enfocado a fijar los elementos de los que consta un sistema, las relaciones que mantiene, los mecanismos que generan los cambios y las adaptaciones que realiza, las fronteras, pero también las conexiones que establece con el medio tanto físico como sociocultural. (Álvarez Munárriz, 2015: 41; Siegenfeldt y Bar Yam, 2020: 10). Partiendo de estos supuestos nos ocupamos de las diferentes dimensiones que, de manera directa o indirecta, están afectando al sistema familiar. La permeabilidad de la sociedad actual a estos avances se ha acrecen- tado en los últimos años si tenemos en cuenta que estamos viviendo en una era de auténtica ebullición de la llamada "industria de la felicidad" y del wellness o wellbeing. Nos vemos impulsados a satisfacer todas nuestras necesidades y anhelos para alcanzar una plenitud vital idealizada, como si se tratara de un dogma o mandato moral que recae en nuestras conciencias. El bienestar y la salud como imperativos sociales, no sólo la ausencia de enfermedad o padecimiento alguno, se inscriben en esa plenitud inalcanzable que ha sido mitificada por los medios de comunicación, la sociedad de consumo y el capitalismo exacerbado (Milanovic, 2020: 12). Ambos conceptos, tal y como se están dibujando en nuestra sociedad, encajan a la perfección con los relatos dominantes en torno a un deseo de mejoría infinita, de perfección, de ausencia de sufrimiento y dolor, de aprecio por vernos y sentirnos bien, de encanto inusitado por mostrar a los demás nuestras vidas armoniosas y completas, como base de una forma legitimadora del reconocimiento social y de una validación personal genuina. Hemos ido incorporando estos valores como estándares, patrones y hábitos de un estilo de vida hiperbólico en la búsqueda del placer, en la consecución de la satisfacción inmediata, de la alegría y el disfrute perennes. La tecnociencia con sus avances parece allanar el camino hacia este ideal, alimenta este nuevo "orden moral" y la noción de "paraíso terrenal" donde la salud y del bienestar completos están a nuestro alcance, y se retroalimenta a su vez de los anhelos sociales que acabamos de describir.

Consideraciones previas sobre la familia nuclear y la pareja

La familia nuclear en nuestra sociedad sigue siendo una institución en torno a la cual se articula una buena parte de nuestra vida y de nuestras relaciones. Es un "refugio" -por alusión al término acuñado por el sociólogo norteamericano (Lasch, 1984)- en un mundo no diremos que despiadado, como lo describió este autor en el título de su obra, pero sí insertada en una realidad social dinámica, compleja, cambiante y en ocasiones incierta y amenazante como en estos tiempos de sindemia. Pese a todo ello, y los cambios que se vienen produciendo en el 
sistema familiar, la familia nuclear conserva dos funciones preeminentes que no se han visto alteradas con el paso del tiempo: por un lado, contribuye decisivamente a asegurar la supervivencia física del individuo, y promueve, a través de un mecanismo generacional de interacción/aprendizaje la construcción de una identidad sociocultural y la transmisión de determinados valores y creencias (Froufé, 1995; Musitu, 1995).

Es seminal el trabajo macro-comparativo llevado a cabo por G. Murdock en la década de los sesenta del siglo pasado desde el Institute of Human Relations de la Universidad de Yale sobre más de doscientas cincuenta sociedades repartidas por todo el planeta, concluyó que la familia nuclear era la forma más elemental de vida doméstica hallada de entre el amplio abanico de estructuras y sistemas familiares comparados. Esta pionera investigación crosscultural condujo también a la elaboración de una definición ya clásica de lo que entendemos por familia nuclear: "The family is a social group characterized by common residence, economic cooperation and reproduction [...] It includes adults of both sexes, at least two of whom maintain a socially approved sexual relationship, and one or more children own or adopted" (Murdock, 1965: 1). El estudio de la familia nuclear en el ámbito de las Ciencias Sociales y Humanas ha sido profuso y ha generado, y lo sigue haciendo en la actualidad, incontables discusiones acerca del sentido del propio término, de su supuesta universalidad, de su adecuación y permanencia desde una perspectiva histórica, socioantropológica y transcultural, de su capacidad descriptiva y explicativa a la hora de comprender cómo se organizan las relaciones dentro del propio sistema familiar nuclear, etc. Sigue siendo la célula básica de nuestra sociedad, pero al mismo tiempo sobre ella se han focalizado todo tipo de teorías y postulados que intentan dar respuesta a la evidencia de que se trata de una institución permeable, en continuo y constante reajuste, sometida a todo tipo de fuerzas o influencias procedentes de distintos órdenes de la vida como el social, el económico o el demográfico. Desde esta perspectiva hay autores que prácticamente desde la segunda mitad del siglo veinte vienen hablando de la "transformación", la "crisis", el "declive", o lo más pesimistas, de la "desaparición" de la familia nuclear, como resultado de la denominada segunda transición demográfica, o de otros fenómenos como la separación o el divorcio, las políticas familiares desarrolladas en muchos países occidentales que han debilitado la familia como estructura básica de solidaridad y apoyo social, o el individualismo galopante en una sociedad de consumo abiertamente hedonista y narcisista (Alberdi, 1995; López de Lera e Izquierdo, 1995; Popeone, 1988 y 1993). Casi invariablemente la familia se ha visto como una institución frágil inmersa en una crisis perpetua, pero la "inestabilidad" no es siempre algo negativo, al contrario, la familia se puede entender como un elemento creativo de la sociedad (Strathern, 1995: 29). Algunos autores han preferido hablar de una nueva era postnuclear (Campo, 1991: 15) donde predomina la capacidad de elección de las personas en cuanto a las formas y estilos de vida y convivencia que deciden adoptar, la diversidad en las estructuras familiares, las relaciones entre los miembros de la pareja mucho más desinstitucionalizadas y regidas por un compromiso más emocional y afectivo que formal, o la aparición de realidades familiares a priori desligadas de un sentido del parentesco asociado a la descendencia en su versión tradicional, como los núcleos familiares derivados de un matrimonio o la unión de hecho entre dos hombres o dos mujeres, o bien fenómenos tan interesantes como la monoparentalidad masculina y que se han mostrado como ámbitos para la reflexión profunda y necesaria desde las propias políticas sociales que se implementan y se dirigen a la familia (Avilés, 2015; Pichardo Galán, 2008).

En nuestra cultura parece instalarse un orden colectivo en consonancia con un proceso más amplio y complejo de desinstitucionalización de la vida en pareja. Curiosamente en una sociedad donde predomina el gustarse, para unirse a otra persona, donde la seducción se ha vuelto soberana y las emociones todo lo presiden, "sentirme bien", "sentirme queridos o amados" son absolutos del ethos consumista que impera, una sociedad donde como señala G. Lypovetsky, se expanden el ciberligue y el hiperconsumismo emocional y se ha generalizado en prácticas como el zapping relacional o el ligue-surfing (Lypovetsky, 2020: 97) los hijos parecen caer en una aparente contradicción. Son vistos como una carga, como un obstáculo para disfrutar de nuestra libertad, pero al mismo tiempo representan una cierta forma de reputación o éxito social. Sería la prueba de que la pareja ha fructificado de alguna manera, ha cumplido una finalidad social dirigiéndose hacia un proyecto común, en el que se invierte mucho esfuerzo y dedicación como si ahora se tratara de un "lujo" o un bien preciadísimo. En ello sin duda influye el hecho de que tener hijos, ser padre o madre, es una decisión personal que se proyecta en la vida de la pareja como una vía de realización común. No se trata de una obligación o de un mandato, sino del deseo de alcanzar un logro o una meta que valoramos por lo que representa y por las implicaciones que tendrá en nuestras vidas. La desnormativización de pareja en un sentido social, no ha supuesto la pérdida del interés por tener descendencia. Cierto y verdad es que esta aspiración entra en un proceso de toma de decisiones más o menos calculado en el que intervienen múltiples factores: cuántos hijos quiero tener, cómo voy a ocuparme de ellos, qué tipo de vida les quiero proporcionar, con qué recursos y apoyos sociales y familiares cuento, etc. Tener hijos se ha acomodado en cierto sentido a la propia lógica de una cultura consumista. Se han convertido en el fruto "deseado", en una aspiración que orienta al individuo hacia la búsqueda infatigable y planificada de una felicidad o plenitud personal, del sentido de la propia vida. Un sentido que ahora "compramos" y que la industria de la fertilidad nos puede proporcionar gracias a la tecnociencia.

Durante bastante tiempo sobre la familia nuclear ha planeado la idea de que los hijos eran el resultado esperable y deseable de la relación conyugal o de pareja, y más concretamente el fruto del éxito del matrimonio. Un matrimonio revestido en ocasiones de una idealización romántica exagerada. Un gran cambio que se ha producido en las últimas décadas es precisamente la desinstitucionalización del matrimonio como se ha mencionado, y especialmente con relación a los hijos como propósito principal y casi exclusivo del vínculo afectivosexual entre la pareja. Las relaciones de pareja se han transformado vertiginosamente. 
Para empezar la pareja es ahora el centro de todo y sobre ella recae una enorme presión. La aspiración que los individuos incorporamos a nuestras vidas de hallar a toda costa la felicidad completa la trasladamos a la esfera de la pareja. La idea de que esa felicidad puede emanar de una relación afectivosexual convierte a la pareja en el reducto del bienestar absoluto del que habla Tamara Tenenbaum, que representaría la armonía conyugal como forma de éxito y plenitud personal (Tenenbaum, 2021: 71). La familia nuclear en la actualidad es una institución o una realidad viva. Su supuesto declive es más bien un mito, como ya lo propugnó E. L. Klain, si además atendemos a su inherente capacidad de regeneración y transformación y admitimos de paso el impacto que otros fenómenos sociales incipientes están teniendo en torno a lo que denominamos como "cultura de los cuidados", las relaciones intergeneracionales, la existencia de sistemas familiares abiertos plurinucleares que rompen con la idea de una única unidad conyugal y/o de convivencia, o atendemos más a las evidencias científicas que a debates exageradamente emocionales (Furstenberg y Cherlin, 1991; Guerrero, 2016; Klain, 1990; Houseknecht y Sastry, 1996). La idea es dirigir el foco sobre la familia nuclear pensando que es una institución que se acomoda a determinadas circunstancias o cambios, que es resiliente y que evoluciona en cierta dirección (Palmer y Coe, 2020). Ello nos hace pensar que no es una cuestión que deba preocuparnos o prevenirnos como si estos cambios fueran los signos inequívocos de la aniquilación o el exterminio de la misma, sino muy al contrario, debe ser un acicate, un reto para la investigación sociocultural y la posibilidad cierta, como se verá en este artículo de que los avances por ejemplo en la biotecnología humana nos conducen a dilucidar cuestiones transcendentales más allá de la familia nuclear y que se aproximan al sentido de la naturaleza humana y la vida, de lo que significa ser persona o de las creencias culturales y los valores sociales.

No existe una relación directa entre matrimonio y descendencia, lo vemos por ejemplo en la cohabitación antes del matrimonio, en los periodos libres de descendencia, en el compromiso de felicidad mutua y disfrute que la pareja se concede así misma sin que "tener hijos" sea necesariamente un objetivo prioritario como sucede en las denominadas parejas child-free. Sin embargo, más allá de las formas de convivencia conyugal que se dan en nuestra sociedad, las parejas child-free aun tratándose de una opción convivencial alternativa, representan en cierto sentido la capacidad que la pareja ha adquirido en lo que se refiere a la conducción o la toma de decisiones respecto de su propia vida, desligada por completo de un destino o itinerario único que son los hijos. No obstante, la pareja se ve al mismo tiempo interpelada por un discurso de igual o similar intensidad que vincula la armonía y el éxito de la pareja con el hecho de tener hijos; hijos por otra parte sanos, perfectos, buenos, inteligentes, etc. Cuando hablamos por tanto de tener hijos y criarlos es más que un deseo en sí mismo, es una aspiración y es un hecho reconocido como un valor por la pareja asociado a la idea de compromiso, de felicidad mutua, de estabilidad, de proyección en el tiempo de la relación, de respuesta a un ciclo vital que se inicia en la pareja y continúa con la paternidad y la maternidad, etc. Por otra parte, la descendencia no requiere a su vez de la existencia de una relación de pareja como tal, ni ser la resultante de un plan que despliega la pareja con base a una serie de valores y expectativas. Las clínicas de fertilidad se dirigen a sus potenciales usuarios con eslóganes publicitarios tipo: “'Mujer soltera a los 40 ? Puedes ser madre si quieres". Estamos en la lógica de una sociedad que instruye a los individuos en la máxima del "tú puedes", es más del "tú puedes todo", todo está a tu alcance y si no lo obtienes has fracasado o eres culpable por no lograr tus objetivos vitales (Han, 2012). Frente a esa debacle emocional que nos provoca inquietud la industria de la fertilidad se erige en una alternativa óptima. Los hijos son un absoluto de plenitud, una fuente de gratificación afectiva y de felicidad. De alguna forma los hijos dotan de sentido nuestra existencia, y también la completan confiriéndole unas funciones que contribuyen a nuestro desarrollo en ese itinerario de búsqueda de la felicidad. Los hijos ya no nacen únicamente del amor, se han escindido además de una relación de pareja como conditio sine qua non. En este proceso son determinantes las contribuciones de la Ingeniería genética que pasamos a examinar.

La clonación humana

En esta contribución continuamos, actualizamos y ampliamos una investigación que habíamos realizado. Resaltamos el proyecto pionero en España de "Biotecnología y familia". En él anticipamos el carácter empresarial de la industria biomédica que ha adquirido la clonación humana. De ahí que como una contextualización previa vamos a dedicar unas breves líneas a los trabajos de L. Álvarez y J. Guerrero. Una de las virtudes del trabajo realizado iniciado en 1996 por el grupo de investigadores de la Universidad de Murcia, es que aportó determinados datos procedentes del trabajo de campo que en aquel momento nos permitieron atisbar algunas de las características que estaban presentes en la representación sociocultural de la Biotecnología humana y de las Técnicas de Reproducción Asistida (TRA). Todo ello estaba ligado al sentido de la familia y del parentesco de una forma indudable, como a la propia concepción y al significado cultural del género y también de la paternidad y la maternidad. Pudimos destacar cómo la visión acerca de la reproducción asistida se encontraba mediatizada en muchos aspectos por la construcción sociocultural de la familia. Otra cuestión interesante que se desveló en este trabajo es que las personas, a la hora de valorar la trascendencia de estos avances para la sociedad, se ubicaban en un rango de actitudes que iban desde el rechazo hasta la casi total o plena aceptación de los mismos. Las actitudes o disposiciones para valorar positiva -o negativamente en otros casos- estos avances correlacionaban en buena medida con las diferentes percepciones acerca de la familia, el matrimonio, los hijos, las relaciones 
de pareja, la concepción o la propia sexualidad (Guerrero, 1999: 144-145).

El profesor J. Bestard en su obra Parentesco y Modernidad (1998) incluyó al final de su libro un capítulo titulado "Artificial y natural: ¿qué queda de la naturaleza?" que dedicó esencialmente a reflexionar acerca de cómo la biología reproductiva había dejado de proporcionar modelos de certidumbre respecto del parentesco, indicando que el parentesco había perdido su referente natural (cópula sexual) para disolverse en la manipulación técnico-cultural (la fecundación in vitro). Centrado en el concepto de parentesco, advierte cómo al separarse la reproducción humana de la relación sexual aparecen por ejemplo distintas categorías de maternidad como la maternidad "biológica", la maternidad "uterina" o "sustituta" o la maternidad "social", de igual manera que en la ecuación del parentesco se introducen nuevos actores como el donante de esperma o la donante de óvulos (Bestard, 1998: 214). Con estas aportaciones se inauguraba en cierto sentido una línea de trabajo en la antropología social en nuestro país, vigente hasta nuestros días, que insiste en la indagación y el análisis pormenorizado de las variantes que se producen en la "cultura del parentesco" con relación a la concepción, la maternidad/paternidad, los donantes, la industria reproductiva, etc., y sus múltiples implicaciones en la producción del parentesco y el sistema de valores y creencias que lo sustenta (Guerrero, 2008).

Los logros de la Biotecnología humana en una sociedad "aspiracional" como la nuestra, con elevadas expectativas y cotas de salud, bienestar y calidad de vida, son enormemente apreciados. Su contribución en la erradicación de graves enfermedades, la solución de dificultades en la concepción humana derivadas en ocasiones de la esterilidad o de otras patologías, la regeneración de órganos, la prevención de enfermedades, etc. han precipitado un auténtico tsunami informativo en revistas científicas divulgativas y un debate social y científico de primer orden. En el tema de la familia la visión sistémica se fundamenta en los principios de la evolución y las personas que la componen son concebidos como seres evolutivos. Es la genética la que ha sustituido a la Física como modelo de ciencia. Anteriormente la realidad humana y social se explicaba a través de los átomos, pero en el presente a través de los genes y los epigenes. Es por tanto evidente que la rápida emergencia de la Biotecnología ha traspasado algunos límites de la cultura, las creencias y la ética. La clonación es un ejemplo actual alrededor del que giran muchos debates ya que se ha vuelto difícil encontrar soluciones a distintos problemas relacionados con la clonación reproductiva. Los riesgos para la salud de los seres humanos y la pérdida de la dignidad siguen estando o formando parte del debate central, aunque claro está pueda haber otros problemas lógicos y legales relacionados con la clonación reproductiva. Además, los científicos no tienen suficiente información sobre el impacto de la clonación en el bienestar mental y biológico de los clones, y el concepto eugenésico podría utilizarse en animales para beneficio del ser humano (Bahadur, 2020: 3; Huberman, 2020: 10).

Nos colocamos en este espacio de investigación, pero nos apoyamos en el paradigma epigenético tanto celular como molar, es decir, conjugando la lente analítica y sin- tética en nuestra metodología. El enfoque ecosistémico proporciona una visión integral que consideramos esencial y necesario tanto para superar el reduccionismo neodarwinista, así como para avanzar en el conocimiento del individuo dentro del medio socioecológico en el que vive (McLaren, 2019: 428). Se observa que los investigadores familiares están incorporando factores genéticos en sus investigaciones con una frecuencia cada vez mayor. Incluyen por ejemplo contribuciones de las perspectivas genética conductual, genética molecular y epigenética, lo que refleja la diversidad de metodologías que se están aplicando actualmente al estudio de las contribuciones genéticas a los procesos y resultados familiares. Es tanto un reconocimiento de la creciente prominencia de los factores genéticos en los modelos familiares como un esfuerzo por destacar diferentes enfoques y fomentar una mayor polinización cruzada entre enfoques. El enfoque evolutivo de la familia se ocupa de los intereses y preferencias de los individuos que buscan formar familias y de los miembros de la familia (Alger y Cox, 2019: 5). Este enfoque de la familia explica el impacto que ha tenido y sigue teniendo la Biotecnología, especialmente su versión más avanzada de Edición del genoma (CRISPR). En el presente es la clonación terapéutica la que sigue teniendo una enorme influencia en el ámbito de la familia. Es la que ofrece un impacto más directo en la salud humana en los miembros de esta institución a través de la medicina de precisión regenerativa (Betzig, 2020).

En la clonación terapéutica se produce la creación de copias de células madre para curar enfermedades. Se clona un embrión para cultivar células, pero no se genera un nuevo organismo. Se experimenta sobre embriones y se dispone para fines de experimentación distintos al proyecto parental. En la actualidad es difícil técnicamente saber qué óvulos serán fecundados a continuación de la hiperestimulación ovárica, ya que cada vez se recoge un número indeterminado de ovocitos (de cero hasta alrededor de veinte, con una media de cuatro). El número de embriones implantados en general es de tres, lo que deja eventualmente algunos embriones disponibles (embriones supernumerarios) que serán congelados. Estos embriones supernumerarios pueden ser objeto de un proyecto parental para una nueva tentativa de transferencia de embriones, bien de un donante a otro, o bien se pueden destruir o incluso abandonar en la institución que realiza investigación. $Y$ en toda esta cadena se puede producir problemas éticos, bien generados por implantar embriones que sean de diferentes donantes, o bien por el pago a los donantes y/o por el requerimiento esencial del informe consentido del donante y receptor y por el registro del niño que sería similar al de cualquier otro nacimiento, con la única excepción de los títulos a heredar que no pueden ser heredados como resultado de tales tratamientos. La originalidad, unicidad y singularidad del embrión explica el rechazo de esta práctica por diferentes autores. Cada individuo es uno, su existencia sigue una trayectoria particular de expresión del mensaje genético. Y es único y diferente a cualquier otro, no sólo por la combinación única de genes que hereda de sus progenitores sino por las fluctuaciones propias de su trayectoria, lo que explicaría por qué los gemelos con idéntico patrimonio genético son distintos (López Moratalla, 2010: 128; Vidal Casero, 2010: 7). A pesar de estos reparos la 
Sociedad Internacional de Investigación de Células Madre ha preparado un borrador de recomendaciones para sacar dicha investigación de una categoría de actividades científicas "prohibidas" y pasar a una clase de investigación que puede permitirse después de una revisión ética y según las regulaciones nacionales. Piden que se anule la prohibición de los 14 días para poder seguir modificando embriones. $Y$ en muchos laboratorios se sigue intentando la clonación reproductiva. Hasta la fecha se ha intentado y se ha afirmado haber realizado la clonación reproductiva, pero de hecho ningún ser humano ha sido clonado con éxito. Está prohibida en todos los países del mundo por razones de todo tipo entre ellas porque desestabiliza la familia y las relaciones entre sus miembros. El rechazo surgió porque se dedujo que, como afirmo S. Hawkins, también se haría con seres humanos. Sin embargo, la terapéutica y la reprogramación celular parece más prometedora. La propuesta de reemplazar partes del cuerpo humano mediante la inyección de células madre o progenitoras en localizaciones precisas parece más realista, aunque como se ha señalado falta mucho trabajo por hacer antes de que podamos hacer tratamientos eficaces y fiables (López Otín y Kroemer, 2020: 258). Si bien aún se encuentra en fase experimental en este momento, diferentes empresas y grupos siguen afirmando que han sido capaces de hacerlo con éxito con células humanas. Promete un impacto más directo en la salud humana a través del nuevo campo de la medicina regenerativa. En efecto, en el año 2020 se votó y aprobó en el estado de California de EEUU la Proposición 14 por la que se permitía la financiación, investigación y tratamiento con células madre embrionarias. (Goldstein y Klein, 2021; Weintraub, 2020; Hyun et al., 2021). No pretenden crear organismos clónicos sino emplear embriones para producir células madre para curar enfermedades. Muchos embriones han sido manipulados, cultivados, sometidos a diagnóstico genético preimplantacional (DGP) y luego congelados. En el laboratorio del University College London como han destacado algunos autores se han utilizado células madre para hacer crecer partes del cuerpo y reparar o reemplazar quirúrgicamente el tejido dañado, incluidos los conductos lagrimales, las tráqueas y los vasos sanguíneos (Reilly, 2021; Berger, 2021). No sabemos cuántos intentos se han hecho para evitar el rechazo inmunológico, pero se usan embriones que tengan estrecha relación familiar. Se tienen, por tanto, que destruir los embriones para obtener este tipo de células. Se puede constatar que son las personas que al nombrar el término «clonación» lo consideren una monstruosidad. Así ocurrió cuando se clonó a la oveja «Dolly» en 1997. La clonación terapéutica da lugar a la destrucción de un embrión después de extraer las células madre y esta destrucción ha suscitado controversia sobre la moralidad del procedimiento. Algunos argumentan que en el debate de los pros y los contras superan a los contras en el tratamiento de la enfermedad, mientras que otros han comparado la destrucción con un aborto. Otros afirman que esto no cambia el hecho de que el embrión podría ser un ser humano y por lo tanto la destrucción del embrión no es diferente a la destrucción de una vida humana.

En el presente la Ingeniería genética comienza a recibir una valoración positiva. Así en el capítulo que trata sobre la edición del genoma de las plantas, Detlef Weigel del Ins- tituto Max Planck de Biología del Desarrollo explica que la tecnología puede producir nuevas variedades de plantas que son más resistentes a los herbicidas o más tolerantes. El documento de debate concluye que los cultivos editados por el genoma no deberían estar cubiertos por la Directiva de ingeniería genética de la UE si los cambios causados por la edición del genoma no pueden distinguirse de las mutaciones naturales. Esta afirmación indica la valoración positiva que paulatinamente está recibiendo la biotecnología. La justificación es muy sencilla: afecta a la salud y la vida de los ciudadanos agobiados y atemorizados por la Covid19. Ese cambio se debe a que todas las vacunas que han sido aprobadas, así como los antivirales contra la sindemia de Covid 19 están diseñadas y elaboradas con técnicas de ingeniería genética de forma más rápida y eficiente. En esta línea se afirma: "Las restricciones a la investigación ética y valiosa parecen ser particularmente absurdas durante una pandemia mortal. La investigación sobre virus como el VIH y el SARS-CoV-2 (síndrome respiratorio agudo severo coronavirus 2 ) puede beneficiarse enormemente del trabajo con ratones que utilizan células madre y tejidos fetales humanos para generar un sistema inmunológico similar al humano" (Goldstein y Klein, 2021: 251). Ha sido un avance decisivo la reciente creación de quimeras mono-humano, la introducción de células humanas en embriones de primate que crecieron hasta un lograr un periodo significativo de veinte días. Supone un paso más para estudiar la salud y las enfermedades humanas, el trasplante de órganos, el descubrimiento de fármacos y muchas más aplicaciones de investigación (Tan et al., 2021: 2022).

El impacto de la Covid-19

Esta enfermedad ha afectado a todos los ámbitos de la vida social, pero de modo especial a la familia. La pandemia de coronavirus (COVID-19) ha alterado la vida familiar en todo el mundo, con un impacto psicológico notable en la vida de las personas como describe H. Carpintero: "Sus vidas se han angostado, sus temores han crecido, $y$, al tiempo que se han serenado al verse vivos y sanos, la amenaza de un futuro sombrío y de una vida personal y socialmente deshecha pone a innumerables personas ante una situación de estrés, inseguridad e indefensión" (2020: 55). Cierres de escuelas, trabajo remoto, distanciamiento físico: es mucho para todos, pero especialmente para los padres de familia. La COVID-19 nos ha quitado nuestras rutinas diarias de trabajo, hogar y escuela. Esto es difícil para todos y elaborar nuevas rutinas puede ayudar. La pandemia de COVID-19 representa una grave amenaza para el bienestar de los niños y las familias debido a los desafíos relacionados con la interrupción social, como la inseguridad financiera, la carga de cuidado y el estrés relacionado con el confinamiento (por ejemplo, hacinamiento, cambios en la estructura y la rutina). Es probable como se viene sugiriendo que las consecuencias de estas dificultades sean duraderas, en 
parte debido a las formas en que el riesgo contextual impregna las estructuras y procesos de los sistemas familiares (Prime et al., 2020: 630). La Sociedad Española de Fertilidad (SEF) recomendó el cese de la mayor parte de las actividades de los Centros de Reproducción Asistida por la sindemia de la Covid 19 por un posible colapso hospitalario y de recursos sanitarios. A quienes había comenzado el tratamiento o tenían previsto hacerlo se les aconseja contactar con el Centro para la información pertinente incluso se ofrece la posibilidad de hacerlo a través de videoconferencia. Se comunica que se siguen todas las recomendaciones locales, nacionales e internacionales. Las que habían iniciado el proceso prosiguieron, pero con medidas de seguridad. Se ha creado un protocolo prevención y seguridad que tanto como garantiza la que visita la clínica como la de los profesionales que la realizan. Se han reiniciado para el imparable deseo de ser madre se pueda hacer realidad. Es evidente que ha cambiado la vida familiar. Es cierto que el Covid19 no respeta las fronteras entre las naciones ni la clase entre las personas: todos somos iguales frente al riesgo de este maligno síndrome. Pero también es muy cierto que persiste e incluso ha agravado la desigualdad socioeconómica (Beland et al., 2020). Para explicar este dato evitamos la falsa y simplista dicotomía que se ha expandido en el campo de las Ciencias Sociales: excluidos/incluidos, los que tienen más/menos, ganadores/perdedores, privilegiados/desgraciados, etc. Desde una perspectiva cultural reconocemos la validez de los tres niveles de investigación en Ciencias Sociales que consideramos indisoluble y estrechamente conectados -macro, meso y micro- (Gardini, 2020: 53). Nos centramos en el nivel micro de la familia que sigue siendo esencial pues se mantiene como la célula básica desde la que se construyen todas las sociedades del mundo. Consideramos que una persona solitaria y aislada es en gran medida una ficción. Para reducir la desigualdad familiar se apuesta por una política justa e inclusiva globalista. Es una apuesta de futuro, pero de manera inmediata se promueve una ayuda urgente a las familias que soportan unas condiciones desfavorables. Como se viene insistiendo por parte de algunos autores la adopción de medidas a corto plazo ante la crisis no debe perder de vista la protección de las familias de bajos ingresos. Así, las medidas de ayuda a los ingresos deberían ser suficientemente amplias para cubrir a los trabajadores vulnerables y a las empresas que los emplean (Belser, 2020). Para superar este impacto se apela al concepto de resiliencia. La resiliencia familiar se caracteriza por el funcionamiento de la competencia después de los desafíos. El modelo de resiliencia familiar sugiere que una combinación de detalles específicos de riesgo, protección y vulnerabilidad familiar dentro de los sistemas de significado familiar y ecosistemas más amplios explica la variación en el funcionamiento de las familias y sus miembros después de la adversidad. Los enfoques de resiliencia familiar asumen que todas las familias tienen fortalezas que pueden cultivarse o movilizarse para enfrentar la adversidad (Henry, Morris y Harrist, 2015). Para conseguirlo debemos conocer los riesgos y las dificultades que ha generado.

En lo referente a las personas del sistema familiar ha cambiado la vida familiar y las relaciones, así como cómo estos cambios afectan el estrés percibido entre hombres y mujeres casados. Este estudio investigó los cambios en el uso del tiempo en familia, el trabajo doméstico, el cuidado de los niños, las actividades de ocio, los ingresos y los gastos junto con las relaciones entre los cónyuges e hijos se puede hablar de miedo, ansiedad e incertidumbre. En lo referente a los hijos: El ajuste del niño se determina de forma múltiple, con influencia de ambos factores distales (por ejemplo, trastornos sociales debido a COVID-19) y procesos proximales (por ejemplo, relaciones con otras personas cercanas, como familiares miembros, maestros y / o compañeros) (Prime et al., 2020: 632; Chin et al., 2020: 451).

Superaremos la pandemia y recuperaremos las reuniones cara a cara, pero habrá cambiado nuestra manera de realizarlo porque el impacto de nuestro uso de los dispositivos digitales nos han podido convertir en ciudadanos del paisaje virtual. Las actividades de ocio han cambiado hacia más tiempo para mirar televisión o medios en línea y jugar juegos en línea y menos tiempo para actividades al aire libre, compras y reuniones de amigos. Aproximadamente el $38 \%$ de los encuestados informó una reducción en los ingresos familiares y el $22 \%$ informó un aumento en la deuda de los hogares. La mayoría no experimentó cambios en la calidad de las relaciones con los cónyuges e hijos, aproximadamente el $20 \%$ de la muestra informó un cambio positivo en las relaciones con los cónyuges e hijos (Chin et al., 2020; Stieger, Lewetz y Swami, 2021; Yanez, 2021). En muchas familias se necesitará una desintoxicación digital para que sus miembros no se conviertan en seres que solamente desarrollan una identidad virtual, pierdan la necesidad del contacto personal y anticipen la llegada del Homo numericus (Desmurget, 2020: 9; Mano, 2020: 457).

Estos datos nos obligan a preguntarnos sobre cuál será el futuro de la familia después del tremendo impacto que ha provocado este virus. De nosotros depende la construcción de una sociedad y una familia basada en el contacto personal o un mundo distópico de tipo virtual. No encontramos evidencia de que la situación laboral y los arreglos laborales estén relacionados con niveles más altos de estrés familiar y violencia en el hogar debido al confinamiento, lo que sugiere que el trabajo remoto a gran escala no conduce a la violencia familiar. En contraste, encontramos que la incapacidad para cumplir con las obligaciones financieras y mantener los lazos sociales aumenta significativamente el estrés familiar y la disfunción doméstica (Beland et al., 2020; Lebow, 2020). Es un dato que sirve para indicar que no se producirá un cambio sustancial o revolución sino una adaptación a la nueva situación post-pandémica. Señalaba J. Edwards una idea que se repite en el análisis de esta realidad desde las Ciencias Sociales, y es que las culturas poseen un potencial de adaptación prácticamente infinito y los hechos biológicos de la reproducción humana son continuamente asimilados y representados de muy diversas maneras en las diferentes regiones del mundo. Desde una visión nada pesimista J. Edwards confiere a estas innovaciones un valor cultural indudable, y en lo que afecta a la institución del parentesco, por ejemplo, nos recuerda que ésta es infinitamente maleable y plástica, recaen sobre ella complejos significados y resulta tremendamente híbrida dado su constante reorganización y recontextualización que proviene en gran medidas de trascendentales y relevantes cambios sociales, históricos y culturales (Edwards, 
1993: 90). De todas maneras, tendremos que esperar a los resultados de la investigación que la ONU, bajo la dirección de Abrik, ha iniciado sobre "Estudio global sobre el impacto de la pandemia de Covid 19 en la vida familiar de todas las culturas".

La Edición del genoma (CRISPR)

Esta técnica está teniendo una gran repercusión en la institución familiar. Recientemente el premio Nobel de Química del año 2020 reconoció el trabajo de la bioquímica y microbióloga Emmanuelle Charpentier y de la profesora de química y biología molecular Jennifer Doudna por el desarrollo de la tecnología CRISPR/Cas9, o "las tijeras genéticas" como también se la ha denominado popularmente, que permite modificar los genes cortando los fragmentos alterados que se relacionan con la aparición de determinadas enfermedades. El estudio llevado a cabo demostró igualmente que la familia de endonucleasas Cas9 se puede programar con moléculas de ARN individuales, para así escindir sitios de ADN específicos, lo que aumenta la posibilidad de desarrollar un sistema dirigido por ARN simple y versátil para generar rupturas de ADNdc para la selección y edición del genoma.

Esta técnica que posibilita "cortar" $y$ "pegar" secuencias de ADN está progresando de forma vertiginosa e imparable, hasta el punto de que la biotecnología ya es capaz de modificar el "patrimonio genético" de los individuos, aunque todavía haya obstáculos técnicos, científicos y éticos (Charpentier, 2020). A pesar de estas dificultades renace el tecno-optimismo que subraya los avances y el éxito en el uso de las vacunas covid basadas en ARN mensajero, de la IA para predecir el plegamiento de proteinas $y$, sobre todo, de la poderosa herramienta de edición de genes CRISPR. (Álvarez de Luis, 2017: 43; Rotman, 2021: 3). La primera "aplicación" CRISPR para el nuevo coronavirus vino de la mano del laboratorio deFeng Zhang (BROAD-MIT, Boston, MS, USA), el inventor de la técnica de diagnóstico mediante CRISPR Ilamada SHERLOCK (nombre con evidente gancho y doble sentido, que es un acrónimo de las palabras en inglés Specific High-sensitivity Enzymatic Reporter unLOCKing), y que su laboratorio describió en 2017.

La tecnología de ingeniería Genética de Edición del Genoma (CRISP) fue descubierta por primera vez por un grupo de científicos japoneses en 1987 (Ishino et al., 2019: 3499). Más tarde de manera independiente por el científico español F. J. M. Mojica en los años 90 (Mojica y Almendros, 2017: 22). La ingeniería genética está experimentando un impulso renovador. Una década después del Proyecto del Genoma Humano, que no rindió todos los frutos esperados, ha irrumpido una técnica cuyas posibilidades parecen infinitas. CRISPR/Cas9, unas tijeras moleculares que modifican el ADN en puntos escogidos con una precisión sin precedentes, está generando nuevas esperanzas. La estrategia ya está revolucionando todas las áreas de la inge- niería genética, El descubrimiento de los CRISPR-Cas9 brindaba la solución perfecta. En lugar de tratar de reinventar la rueda, ¿por qué no adaptar las nucleasas programables ya esculpidas por la naturaleza a lo largo de miles de millones de años de evolución? Si las bacterias empleaban CRISPR-Cas6 para introducir cortes de ADN en genomas virales para prevenir infecciones, quizá los científicos podrían emplear CRISPR-Cas9 para introducir roturas de ADN en genomas eucariotas, y así editar genes. armados con el poder de reescribir de manera sencilla y precisa el código genético, científicos y no científicos amenazan con subvertir el orden natural, remodelando el proceso evolutivo mismo al sustituir la mutación aleatoria - el proceso azaroso, sinuoso de la selección natural a lo largo de eones- por una mutación definida y personalizada por el usuario, introducida a voluntad usando la tecnología CRISPR. El resultado: una nueva manera de controlar la dirección en la que va la vida misma. Los detalles científicos son complejos y tienen que ver con esquivar las leyes fundamentales de la herencia descubiertas por Gregor Mendel en el curso de sus experimentos con guisantes. La genética dirigida basada en CRISPR permite a los bioingenieros romper esas leyes "dirigiendo" nuevos genes, junto con sus rasgos asociados, a poblaciones de especies animales a una velocidad sin precedentes. Reparando las mutaciones de ADN directamente en embriones humanos concebidos en un laboratorio a partir de la fusión de un óvulo y un espermatozoide mediante fertilización in vitro (FIV), estos científicos aspiran a crear ediciones génicas heredables que puedan copiarse en todas las células del humano en desarrollo y transmitirse a toda su descendencia futura. Corregir genes en embriones constituye una forma de edición de genes sobre la línea germinal, es decir, sobre las células germinales cuyo genoma puede ser heredado por generaciones futuras. La edición de línea germinal se practica de forma rutinaria en la cría animal porque es la manera más efectiva de crear animales modificados genéticamente $y$, de hecho, los métodos para inyectar CRISPR en embriones de ratones se han perfeccionado en los últimos cinco años. Sin embargo, la idea de realizar experimentos similares en embriones humanos suscita alarma, no solo por el miedo a que se introduzcan mutaciones heredables (línea germinal), sino también por las ramificaciones éticas y societales de una tecnología que podría alterar el genoma humano durante generaciones. Un grupo de investigadores chinos publicó un artículo según el cual, por primera vez en la historia, se había sometido a embriones humanos a edición genética de precisión. Los primeros humanos modificados genéticamente nacieron en China en 2018. La MIT Technology Review publicó un artículo, que informaba que JK había creado "bebés CRISPR". En noviembre de 2018, un investigador chino afirmó que creó los primeros bebés editados genéticamente del mundo, un par de niñas gemelas que supuestamente son inmunes al virus de inmunodeficiencia humana (VIH). El científico, He Jiankui, afirmó que había obtenido el consentimiento de los "pacientes" (los futuros padres) y que se sentía orgulloso de este logro, un marcado contraste con la reacción sumamente crítica de la comunidad científica en general. Esta información obligó a discutir si se debe permitir el uso de CRISPR/Cas9 para editar el genoma de embriones humanos. Hay millones de 
personas que naturalmente tienen mutaciones en CCR5, la más común es la mutación delta-32, que se cree que surgió en el norte de Europa y confiere resistencia al VIH/SIDA. Quizás es por eso que este investigador chino pensó que estaría bien tener bebés con esta mutación. Según él usó la técnica Crisp cas9 para inhabilitar el gen CRC5 para que las niñas naciesen sin la enfermedad del Sida $(\mathrm{VIH})$. Ningún experimento biomédico reciente ha causado más consternación que la creación de He Jiankui de los primeros bebés editados genéticamente en 2018, que fue ampliamente visto como peligroso, poco ético y prematuro, y que llevó a su encarcelamiento en China. Ahora, un comité internacional ha llegado a la conclusión de que los métodos de edición de genes, a pesar de las mejoras sustanciales, aún están lejos de estar lo suficientemente maduros como para introducir de manera segura modificaciones hereditarias del ADN en embriones humanos (Hyun et al., 2021). Entramos en un territorio incierto sin el conocimiento suficiente y sin unos principios consensuados que nos ayuden a caminar por él. Como advierte el filósofo francés Luc Ferry, los progresos de la Tecnociencia en este terreno tienen una envergadura y una rapidez inimaginables, son silenciosos, no llaman la atención de los políticos, apenas la de los grandes medios de comunicación, de modo que prácticamente ocurren a espaldas del común de los mortales y no son objeto de una regulación mínimamente coercitiva (Ferry, 2017; Greely, 2021).

\section{Reflexión final}

Persisten las preguntas y el tiempo apremia: ¿Cómo será la vida familiar en la era post-sindémica? ¿Qué impacto tendrá la clonación y la edición de genes en la vida familiar? ¿Tendrán hijos sin relación sexual para evitar enfermedades transmisibles? ¿Seguirá siendo la familia la célula básica de la sociedad? Si se modifica la línea germinal ¿Cuál será el futuro de la Humanidad? ¿Acaso es una falsa promesa de la tecnociencia? ¿Qué valoración ética se debe realizar de las propuestas a favor modificación de embriones y de la clonación reproductiva? ¿Qué valor tienen los argumentos de los que las rechazan? Es un reto para la cooperación de los científicos en las ciencias naturales y socioculturales seguir avanzando en sus investigaciones para responder a estas preguntas. El objetivo es muy simple: conseguir una relación armónica y favorable con la tecnociencia de la que de manera alguna ni podemos ni debemos prescindir.
Bibliografía

ALBERDI, I. (1995): “Evolución y tendencias de la institución familiar”, Documentación Social. Revista de Estudios Sociales y Sociología Aplicada, 98, pp. 9-23.

ALGER, A. y COX, D. (2019): "Evolution of the family: Theory and Implications for Economics". Conferencia pronunciada en la Toulouse School of Economics. http://publications.ut-capitole.fr/41756/1/ wp_tse_1139.pdf.

ÁLVAREZ MUNÁRRIZ, L. y GUERRERO MUÑOZ, J. (eds.) (1999): Biotecnología y familia. Factores socioculturales y éticos. Murcia, DM.

ÁLVAREZ MUNÁRRIZ, L. (1999): “La familia ante los retos de la Biotecnología", en L. Álvarez Munárriz y J. Guerrero Muñoz (eds.), Biotecnología y familia. Factores socioculturales y éticos. Murcia, DM, pp. 11-45.

ÁLVAREZ MUNÁRRIZ, L. (2001): “Familia y clonación”, Claves de Razón Práctica, 109, pp. 16-21.

ÁlVAREZ MUNÁRRIZ, L. (2015): Categorías clave de la Antropología. Sevilla, Signatura Demos.

ÁLVAREZ de LUIS, A. (2017): Alimentos transgénicos: factores culturales que explican su aceptación o rechazo. Tesis doctoral. Universidad de Murcia.

AVILÉS, M. (2015): “¿Qué es la monoparentalidad? Una revisión crítica de su conceptualización en materia de política social", Cuadernos de Trabajo Social, 28 (2), pp. 211-223.

BAHADUR, S. (2020): "Biomedical Technologies, Eugenics and Human Cloning: Public Health Law and Legal Issues in Health Practice", Journal of Rehman Medical Institute, 3 (3-4), pp. 1-10.

BELAND, L. Ph. et al. (2020): "COVID-19, Family stress and domestic violence: Remote work, isolation and bargaining power", IZA Discusion Papers, 13332. https://papers.ssrn.com/sol3/papers.cfm?abstract_ id $=3627031$.

BELSER, P. (2020): “El coronavirus revela con crudeza las desigualdades y puede agravarlas". https://news.un.org/es.

BERGER, M. (2021): "How can the world allocate COVID 19 vaccines fairly”. https://penntoday.upenn.edu/news/how-can-world-allocate-covid-19-vaccines-fairly.

BESTARD, J. (1998): Parentesco y Modernidad. Barcelona, Paidós.

BETZIG, L. (2020): “Eusociality in humans”, en L, Workman, L. et al. (eds.), The Cambridge Handbook of evolutionary perspectives on human behaviour. Cambridge, Cambridge University Press, pp. 37-46. https://doi.org/10.1017/9781108131797.005.

CAMPO, S. del. (1991): La "nueva"familia española. Madrid, Eudema.

CARPINTERO, H. (2020): "Pandemia: Perspectiva psicológica” en B. Pandás (ed.), Enciclopedia de las ciencias Morales y políticas para el siglo XXI. Madrid, Imprenta Nacional de la Agencia Estatal, pp. 55-58.

CHARPENTIER, E. (2020): “Neue Cas9-Variante macht Genom-Editierung noch präziser", Max Planck Gesselschaft. https://www.mpg. de/14534697/neue-cas9-variante.

CHIN, M. et al. (2020): "Changes in family life and relationschip during Covid 19 pandemic", Family. Environment Research, 58 (3), pp. 447-461.

DESNURGET, M. (2020): La fabrique du crétin digital: Les dangers des écrans pour nos enfants. París, Seuil.

EDWARDS, J. (1993): "Clones, who are they?", en J. Edwards et al., Technologies of Procreation. Kinship in the age of assisted conception. London/NewYork, Routledge, pp. 86-90.

FERRY, L. (2017): La revolución transhumanista. Cómo la tecnomedicina y la uberización del mundo van a transformar nuestras vidas. Madrid, Alianza.

FROUFÉ, S. (1995): “El protagonismo de la familia ante la transmisión de los valores sociales", Documentación Social, 98, pp. 61-71.

FURSTENBERG, F. y CHERLIN, A. (1991): Divided families: what happens to children when parents part. Cambridge, MA, Harvard University Press. 
GARDINI, G. L. (2020): "COVID 19 and the enduring relevance of political and IR theory", en G. L. Gardini (ed.), The World before and after Covid19. Salamanca-Stockholm, European Institute International Studies Press, pp. 15-22.

GOLDSTEIN, L. S. B. y KLEIN, R. V. (2021): "Stem cells on the ballot", Science, 371 (6526), p. 251.

GREELY, H. T. (2021): CRISPR People: The Science and Ethics of Editing Humans. Cambridge, MIT Press.

GUERRERO, J. (1999): “La biotecnología humana en el debate social de los valores familiares", en L. Álvarez y J. Guerrero (eds.), Biotecnología y familia. Factores socioculturales y éticos. Murcia, DM, pp. 129-152.

GUERRERO, J. (2008): “Concebir, crear y procrear. El discurso cultural en torno a la biotecnología humana y la reproducción asistida", en J. Guerrero, La sociedad extrema. Debates sobre la violencia. Madrid, Tecnos, pp. 163-194.

GUERRERO, J. (2016): "La Familia: realidades y cambio social”, La Razón histórica. Revista hispanoamaeericana de las ideas políticas y sociales, 33, pp. 154-180.

HAN, B. (2012): La sociedad del cansancio. Barcelona, Herder.

HENRY, C. S.; MORRIS, A. S. y HARRIST, A. W. (2015): “Family resilience: Moving into the third wave", Family Relations. Inderdiciplinary Journal of Applied Family Studies, 64, pp. 22-43.

McLAREN, G. (2019): "Health in an Ecological Civilization: Towards a Process Understanding of the Dialectics of Health", Cosmos and History: The Journal of Natural and Social Philosophy, 15 (1), pp. 401-433.

HOUSEKNECHT, S. K. y SASTRY, J. (1996): "Family decline and Child wellbeing: A comparative assessment", Journal of Marriage and Family, 58, pp. 726-739.

HUBERMAN, J. (2020): Tranhumanism. From ancestors to avatar. Cambridge, Cambridge University Press.

HYUN, I. et al. (2021): "Human embryo research beyond the primitive streak", Science, 371 (6533), pp. 998-1000.

KLAIN, E. L. (1990): The myth of family decline. Lexington, MA: Heath.

FERRY, L. (2017): La revolución transhumanista. Cómo la tecnomedicina y la uberización del mundo van a transformar nuestras vidas. Madrid, Alianza.

ISHINO, Y. et al. (2019): "History of CRISPR-Cas from Encounter with a Mysterious Repeated Sequence to Genome Editing Technology", Journal of Bacteriology, 169, pp. 5429-5433.

LASCH. C. (1984): Refugio en un mundo despiadado. La familia, ¿santuario o insitución asediada? Barcelona, Gedisa.

LEBOW, J. L. (2020): "Family in the age of COVID 19", Family Process, 59 (2), pp. 309-312.

LIPOVETSKY, G. (2020): Gustar y emocionar. Ensayo sobre la sociedad de seducción. Barcelona, Anagrama.

LÓPEZ DE LERA, D. e IZQUIERDO ESCRIBANO, A. (1995): “Transformaciones demográficas y nuevas formas de convivencia en la población española", Sociedad y Utopía, 6, pp. 125-184.

LÓPEZ MORATALLA, N. (2010): “El cigoto de nuestra especie es cuerpo humano", Persona y Bioética, 2, pp. 120-140.

LÓPEZ OTÍN, C. y KROEMER, G. (2020): El sueño del tiempo. Barcelona, Paidós.

MANO, R. (2020) "Social Media and Resilience in the COVID-19 Crisis", Advances in Applied Sociology, 10, pp. 454-464.

MILANOVIC, B. (2020): Capitalismo, Nada más. Barcelona, Planeta.

MOJICA, F. J. M. y ALMENDROS, C. (2017): "El descubrimiento del sistema CRISPR cas", Investigación y Ciencia, 493, pp. 22-28.

MURDOCK, G. (1965): Social Structure. New York, Free Press.

MUSITU, G. (1995): "Familia, identidad y valores", Infancia y Sociedad, 30, pp. 230-262.

PALMER, C. T. y COE, K. (2020): "Evolution of the human family", en L. Workman et al. (eds.), The Cambridge Handbook of evolutionary perspectives on human behaviour. Cambridge, Cambridge University Press, pp. 158-166. https://doi.org/10.1017/9781108131797.014.
PAPERO, D. et al. (2018): "Natural Systems Thinking and the Human Family", Systems, 6 (2), pp. 1-10. https://doi.org/10.3390/systems6020019.

PICHARDO GALÁN, J. I. (2008): “Opciones sexuales y nuevos modelos de familia" en A. Téllez Infantes y E. Martínez Guirao (eds.), Sexualidad, género, cambio de roles y nuevos modelos de familia. Elche, Universidad Miguel Hernández, pp. 33-63.

POPEONE, D. (1988): Disturbing the nest: Family change and decline in modern societies. New York, Adine DeGruyer.

POPEONE, D. (1993): “American family decline, 1960-1990: A review and appraisal", Journal of Marriage and the Family, 55, pp. 527-542.

PRIME, H. et al. (2020): "Risk and Resilience in Family Well-Being During the COVID-19 Pandemic", American Psychologist, 75 (5), pp. 631-643.

ROTMAN, D. (2021): "Are you ready to be a techno-optimist again?", MIT Technology Review, 124 (2), pp. 10-13.

SIEGENFELDT, A. F. y BAR YAM, Y. (2020): "An introduction to complex systems science", Complexity, 27, pp. 1-16. https://arxiv.org/ pdf/1912.05088v2.pdf.

STIEGER, S. LEWETZ, D. y SWAMI, V. (2021): "Emotional well-being under conditions of lockdown: an experience sampling study in Austria during the COVID 19 Pandemic", Journal of Happiness Studies. https://doi.org/10.1007/s10902-020-00337-2.

STRATHERN, M. (1995): “New families for old?”, en C. Ulanowsky (ed.), The Family in the Age of Biotechnology. Adershot, Avebury, pp. 27-44.

TAN, T. et al. (2021): "Chimeric contribution of human extended pluripotent stem cells to mono embryos ex vivo", Cell, 184 (8), pp. 20202032.

TENENBAUM, T. (2021): El fin del amor. Amar y follar en el siglo XXI. Barcelona, Seix-Barral.

VIDAL CASERO, M. C. (2010): "La experimentación con embriones", Revista Bioética y Ciencias de la Salud, 4 (2), pp. 1-21.

WEINTRAUB, K. (2020): "California Prop 14 may change lives of sick kids, keep taxpayer funding of stem cell therapy research". https:// eu.usatoday.com.

YANEZ, X. (2019): “¿Qué fue de la clonación?”, https://www.bbvaopenmind.com.

YANEZ, X. (2021): "¿Llevaremos una vida "no presencial” tras la pandemia?", https://www.bbvaopenmind.com. 